\title{
Forward Modeling and validation of a new formulation to compute self-potential signals associated with ground water flow
}

\author{
A. Bolève ${ }^{1,3}$, A. Revil ${ }^{1,2}$, F. Janod ${ }^{3}$, J. L. Mattiuzzo ${ }^{3}$, and A. Jardani ${ }^{2,4}$ \\ ${ }^{1}$ CNRS- LGIT (UMR 5559), University of Savoie, Equipe Volcan, Chambéry, France \\ ${ }^{2}$ Colorado School of Mines, Dept. of Geophysics, 1500 Illinois street, Golden, CO, 80401, USA \\ ${ }^{3}$ SOBESOL, Savoie Technolac, BP 230, F-73375 Le Bourget du Lac Cedex, France \\ ${ }^{4}$ CNRS, University of Rouen, Département de Géologie, Rouen, France
}

Received: 4 May 2007 - Published in Hydrol. Earth Syst. Sci. Discuss.: 8 June 2007

Revised: 26 September 2007 - Accepted: 9 October 2007 - Published: 16 October 2007

\begin{abstract}
The classical formulation of the coupled hydroelectrical flow in porous media is based on a linear formulation of two coupled constitutive equations for the electrical current density and the seepage velocity of the water phase and obeying Onsager's reciprocity. This formulation shows that the streaming current density is controlled by the gradient of the fluid pressure of the water phase and a streaming current coupling coefficient that depends on the so-called zeta potential. Recently a new formulation has been introduced in which the streaming current density is directly connected to the seepage velocity of the water phase and to the excess of electrical charge per unit pore volume in the porous material. The advantages of this formulation are numerous. First this new formulation is more intuitive not only in terms of establishing a constitutive equation for the generalized Ohm's law but also in specifying boundary conditions for the influence of the flow field upon the streaming potential. With the new formulation, the streaming potential coupling coefficient shows a decrease of its magnitude with permeability in agreement with published results. The new formulation has been extended in the inertial laminar flow regime and to unsaturated conditions with applications to the vadose zone. This formulation is suitable to model self-potential signals in the field. We investigate infiltration of water from an agricultural ditch, vertical infiltration of water into a sinkhole, and preferential horizontal flow of ground water in a paleochannel. For the three cases reported in the present study, a good match is obtained between finite element simulations performed and field observations. Thus, this formulation could be useful for the inverse mapping of the geometry of groundwater flow from self-potential field measurements.
\end{abstract}

Correspondence to: A. Revil

(arevil@mines.edu)

\section{Introduction}

Self-potential signals are electrical fields passively measured at the ground surface of the Earth or in boreholes using non-polarizing electrodes (e.g., Nourbehecht, 1963; Ogilvy, 1967). Once filtered to remove anthropic signals and telluric currents, the residual self-potential signals can be associated with polarization mechanisms occurring in the ground (e.g., Nourbehecht, 1963; Bogoslovsky, and Ogilvy, 1972, 1973; Kilty and Lange, 1991; Maineult et al., 2005). One of the main polarization phenomena occurring in the ground is ground water flow (e.g., Ogilvy et al., 1969; Bogoslovsky, and Ogilvy, 1972; Sill, 1983; Aubert and Atangana, 1996) with a number of applications in hydrogeology (Bogoslovsky, and Ogilvy, 1972, 1973; Kilty and Lange, 1991; Maineult et al., 2005; Wishart et al., 2006), in the study of landslides in combination with electrical resistivity tomography (Lapenna et al., 2003, 2005; Perrone et al., 2004; Colangelo et al., 2006), the study of leakages through dams (e.g., Bogoslovsky, and Ogilvy, 1973; Gex, 1980), and in the study in the geohydrology of volcanoes (e.g., Aubert et al., 2000; Aizawa, 2004; Finizola et al., 2004; Ishido, 2004; Bedrosian et al., 2007). The electrical field associated with the flow of the ground water is called the streaming potential (e.g., Ernstson and Scherer, 1986; Wishart et al., 2006) and is due to the drag of the net (excess) electrical charge of the pore water by the flow of the ground water (e.g., Ishido and Mizutani, 1981).

Another contribution to self-potential signals over contaminated ground water is the biogeobattery model developed by Arora et al. (2007) and Linde and Revil (2007) based on the field and laboratory observations reported by Naudet et al. (2003, 2004) and Naudet and Revil (2005). This contribution will not be discussed in this paper.

Over the last decade, the development of very stable non-polarizing electrodes (e.g., Petiau, 2000) has been

Published by Copernicus Publications on behalf of the European Geosciences Union. 


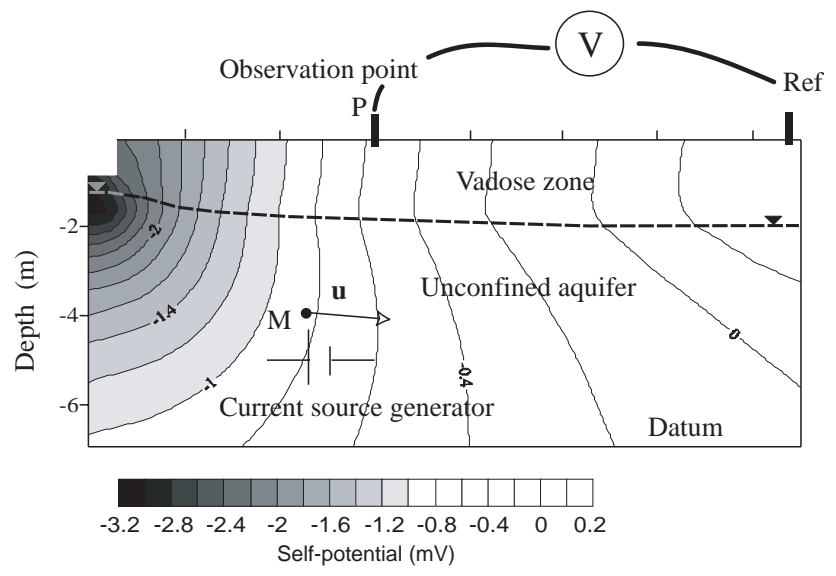

Fig. 1. Sketch of the flow of the ground water from a ditch in an unconfined aquifer and the resulting self-potential distribution. Each point of the ground $\mathrm{M}$ where is a net flow of the ground water water can be represented as a source generator of electrical currents. Each elementary source of current is responsible for an electrical field obtain by solving the Poisson equation. The sum of these electrical fields is sampled at the ground surface using a pair of nonpolarizing electrodes. One of these electrodes is used as a reference while the other is used to measure, at different stations, the value of the electrical potential (called the self-potential) with respect to the reference.

instrumental in the improvement of the self-potential method for applications in hydrogeophysics (see Perrier and Morat, 2000; Suski et al., 2007 and references therein). One of the first numerical computation of streaming potentials due to ground water flow was due to Sill (1983) who used a 2-D finite-difference code. Sill (1983) used a set of two coupled constitutive equations for the electrical current density and the seepage velocity. These constitutive equations were coupled with two continuity equations for the electrical charge and the mass of the pore water. In this classical formulation, the source current density is related to the gradient of the pore fluid pressure and to a streaming current coupling coefficient that depends on the so-called zeta-potential, a key electrochemical property of the electrical double layer coating the surface of minerals in contact with water (e.g., Ishido and Mizutani, 1981; Leroy and Revil, 2004). Later, Wurmstich et al. (1991) performed numerical simulations of the self-potential response associated with the flow of the pore water in a dam.

The classical formulation of Sill (1983) was used by many authors in the two last decades (e.g., Fournier, 1989; Birch, 1993; Santos et al., 2002; Revil et al., 2003, 2004; Suski et al., 2007). While it has proven to be useful, this formulation has however several drawbacks. Intuitively, one would expect that self-potential signals would be more related to the seepage velocity than to the pore fluid pressure. This is especially true in unsaturated conditions for which only the existence of a net velocity of the water phase can be responsi- ble for a net current source density. In addition, the classical formulation does not explain the observed dependence of the streaming potential with the permeability reported by Jouniaux and Pozzi (1995) almong others. It was also difficult to extend the classical formulation to unsaturated conditions (Jiang et al., 1998; Perrier and Morat, 2000; Guichet et al., 2003; Revil and Cerepi, 2004) despite the fact that there is a strong interest in using self-potential signals to study the infiltration of water through the vadose zone (e.g., Lachassagne and Aubert, 1989).

Recently, a new formulation has been developed by Revil and Leroy (2004) and Revil et al. (2005a). This formulation was generalized to a multi-component electrolyte by Revil and Linde (2006), who also modeled the other contributions to self-potential signals for a porous material of arbitrary texture and an electrolyte of arbitrary composition. The formulation of Revil et al. (2005a) was initially developed to determine the streaming potential coupling coefficient of clay-rocks. However, it seems to work fairly well for any type of porous materials. This formulation connects the streaming current density directly to the seepage velocity and to the excess of charge per unit pore volume. This excess of charge corresponds to the excess of charge due to the diffuse layer counterbalancing the surface charge density of the surface of the minerals including the ions sorbed in the socalled Stern layer. Unlike the classical formulation, the new one is easily extendable to unsaturated conditions (see Linde et al., 2007, Revil et al., 2007) and to non-viscous laminar flow conditions at high Reynolds numbers (see Crespy et al., 2007; Bolève et al., 2007). In both cases, an excellent agreement was obtained between the theory and the experimental data. However, so far this formulation has been tested only in the laboratory and not yet on field data.

In the present paper, we test the new formulation of Revil and Linde (2006) to determine numerically, using the commercial finite element code Comsol Multiphysics 3.3 (Comsol, 2007), the self-potential response in the field associated with ground water flow. Three recently published field cases are reanalyzed with the new formulation to see its potential to model field data. The challenge will be to invert selfpotential signals directly in terms of ground water flow in future studies.

\section{Description of the new formulation}

\subsection{Saturated case}

The self-potential method corresponds to the passive measurements of electrical potentials at the surface of the Earth (possibly in boreholes) with respect to a fixed electrode called the reference electrode (Fig. 1). Self-potential anomalies with respect to the reference electrode evidence polarization phenomena occurring in the ground. In this paper, we are interested by the streaming potential contribution to 
self-potential signals that is related to the flow of the ground water (Fig. 1).

We consider a water-saturated mediums isotropic but possibly heterogeneous. In the classical formulation of the streaming potential, electrical and hydraulic processes are coupled through the following two constitutive equations operating at the scale of a representative elementary volume of the porous material (e.g., Ishido and Mizutani, 1981; Morgan et al., 1989; Jouniaux and Pozzi, 1995; Revil et al., 1999a, b):

$\boldsymbol{j}=-\sigma \nabla \varphi-L\left(\nabla p-\rho_{f} \boldsymbol{g}\right)$

$\boldsymbol{u}=-L \nabla \varphi-\frac{k}{\eta_{f}}\left(\nabla p-\rho_{f} \boldsymbol{g}\right)$,

$C=\left(\frac{\partial \varphi}{\partial p}\right)_{j=0}=-\frac{L}{\sigma}$,

where $\boldsymbol{j}$ is the electrical current density (in $\mathrm{A} \mathrm{m}^{-2}$ ), $\boldsymbol{u}$ is the seepage velocity (in $\mathrm{m} \mathrm{s}^{-1}$ ) (Darcy velocity), $-\nabla \varphi$ is the electrical field in the quasi-static limit of the Maxwell equations (in $\mathrm{V} \mathrm{m}^{-1}$ ), $p$ is the pore fluid pressure (in $\mathrm{Pa}$ ), $\boldsymbol{g}$ is the gravity acceleration vector (in $\mathrm{m} \mathrm{s}^{-2}$ ), $\sigma$ and $k$ are the electrical conductivity (in $\mathrm{S} \mathrm{m}^{-1}$ ) and intrinsic permeability (in $\mathrm{m}^{2}$ ) of the porous medium, respectively, $\rho_{f}$ and $\eta_{f}$ are the mass density (in $\mathrm{kg} \mathrm{m}^{-3}$ ) and the dynamic shear viscosity (in Pas) of the pore water, and $L$ is both the streaming current coupling coefficient and the electroosmotic coupling coefficient (in $\mathrm{m}^{2} \mathrm{~V}^{-1} \mathrm{~s}^{-1}$ ), and $C$ (in $\mathrm{V} \mathrm{Pa}^{-1}$ ) is the streaming potential coupling coefficient. The symmetry of the coupling terms in Eqs. (1) and (2) is known as the Onsager's reciprocity (Onsager, 1931). It holds only in the vicinity of thermodynamic equilibrium to ensure the positiveness of the dissipation function (Onsager, 1931).

The hydroelectrical coupling terms existing in Eqs. (1) and (2) is said to be electrokinetic, i.e., it is due to a relative displacement between the charged mineral surface and its associated electrical double (or triple) layer (e.g., Ishido and Mizutani, 1981; Morgan et al., 1989). The streaming current density $-L\left(\nabla p-\rho_{f} \boldsymbol{g}\right)$ is due to the drag of the electrical excess charge contained in the electrical diffuse layer while the term $-L \nabla \varphi$ in Eq. (2) is due to the viscous drag of the pore water associated with the displacement of the excess of electrical charge in an electrical field. In the classical formulation described above, the streaming potential coupling coefficient is related to the zeta potential (a key electrochemical property of the electrical double layer coating the surface of the minerals, e.g., Kosmulski and Dahlsten, 2006) by the so-called Helmholtz-Smoluchowski equation (see Ishido and Mizutani, 1981; Morgan et al., 1989). In situations where the surface conductivity of the grains can be neglected, the Helmholtz-Smoluchowski equation predicts that the streaming potential coupling coefficient does not depend on the texture of the porous material.
The alternative formulation to Eq. (1) is (Revil and Leroy, 2004, Revil et al., 2005a, and Revil and Linde, 2006),

$\boldsymbol{j}=\sigma \boldsymbol{E}-\bar{Q}_{V} \boldsymbol{u}$,

where $E=-\nabla \varphi$ is the electrical field and $\bar{Q}_{V}$ is the excess of charge (of the diffuse layer) per unit pore volume (in $\mathrm{C} \mathrm{m}^{-3}$ ). Equation (4) can be derived by upscaling the Nernst-Planck equation (Revil and Linde, 2006).

An equation for the seepage velocity including an electroosmotic contribution can also be developed based on the new formulation introduced by Revil and Linde (2006). However, this contribution can be safely neglected if the only component of the electrical field is that produced through the electrokinetic coupling (e.g., Sill, 1983). Using this approximation, we recover the Darcy constitutive equation:

$\boldsymbol{u}=-K \nabla H$,

where $K$ is the hydraulic conductivity (in $\mathrm{ms}^{-1}$ ) and $H=\delta p / \rho_{f} g$ is the change in hydraulic head (above or below the hydrostatic initial distribution $H_{0}$ ). Combining Eqs. (3), (4), and (5), the streaming potential coupling coefficient in the new formulation is given by $C=-\bar{Q}_{V} k /\left(\sigma \eta_{f}\right)$ (see Revil and Leroy, 2004, and Revil et al., 2005a). We can also introduce a streaming potential coupling coefficient relative to the hydraulic head $C^{\prime}=\partial \varphi / \partial H=-\bar{Q}_{V} K / \sigma$. These relationships show a connection between the coupling coefficients $C$ or $C$ ' and the permeability $k$ or the hydraulic conductivity $K$. If we use these relationships, the two formulations, Eq. (2) and (4) are strictly equivalent in the saturated case. The only difference lies in the relationship between the streaming coupling coefficient and the microstructure. With the classical formulation, the use of the Helmholtz-Smoluchowski equation predicts that the streaming potential coupling coefficient does not depend on the microstructure. At the opposite, the new formulation predicts that the streaming potential coupling coefficient depends on the microstructure in agreement with experimental data (see Jouniaux and Pozzi, 1995).

The constitutive equations, Eqs. (4) and (5), are completed by two continuity equations for the electrical charge and the mass of the pore water, respectively. The continuity equation for the mass of the pore fluid is:

$S \frac{\partial H}{\partial t}=\nabla \cdot(K \nabla H)$

where $S$ is the poroelastic storage coefficient (expressed in $\mathrm{m}^{-1}$ ) assuming that the material behaves as an electro-poroelastic medium. The continuity equation for the electrical charge is,

$\nabla \cdot \boldsymbol{j}=0$,

which means that the current density is conservative in the quasi-static limit of the Maxwell equations. Combining Eqs. (4) and (7) results in a Poisson equation with a source term that depends only on the seepage velocity in the ground:

$\nabla \cdot(\sigma \nabla \varphi)=\mathfrak{s}$, 


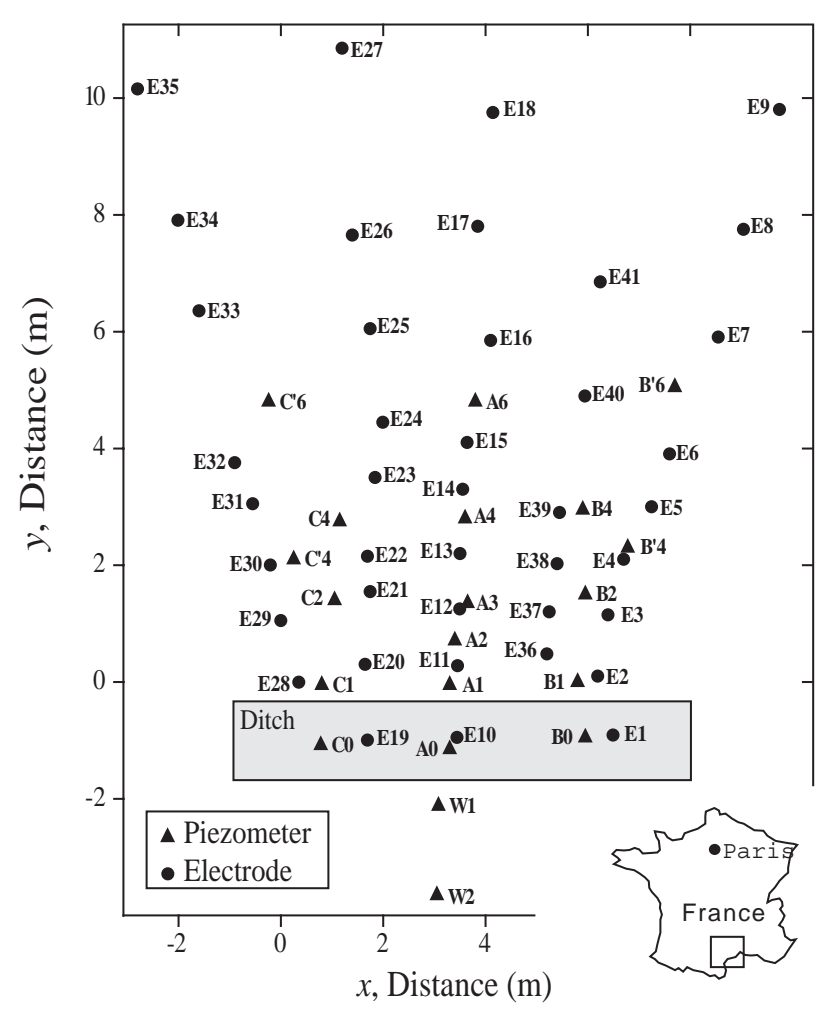

Fig. 2. Top view the test site for the infiltration experiment showing the position of the electrodes and the piezometers. The reference electrode is located $100 \mathrm{~m}$ away from the ditch.

where $\Im$ is the volumetric current source density (in $\mathrm{A} \mathrm{m}^{-3}$ ) given by,

$\Im=\bar{Q}_{V} \nabla \cdot \boldsymbol{u}+\nabla \bar{Q}_{V} \cdot u$,

In steady state conditions, $\nabla \cdot \boldsymbol{u}=0$ and therefore we have,

$\Im=\nabla \bar{Q}_{V} \cdot \boldsymbol{u}$,

i.e., the only source term in steady-state conditions. The shape of the electrical potential streamlines is also influenced by the distribution of the electrical conductivity distribution existing in the ground.

\subsection{Unsaturated case}

For unsaturated conditions, the hydraulic problem can be solved using the Richards equation with the van Genuchten parametrization for the capillary pressure and the relative permeability of the water phase. The governing equation for the flow of the water phase is (Richards, 1931),

$$
\left[C_{e}+S_{e} S\right] \frac{\partial H}{\partial t}+\nabla \cdot[-K \nabla(H+z)]=0,
$$

where $z$ is the elevation above a datum, $H(\mathrm{~m})$ is the pressure head, $C_{e}$ denotes the specific moisture capacity (in $\mathrm{m}^{-1}$ ) defined by $C_{e}=\partial \theta / \partial H$ where $\theta$ is the water content (dimensionless), $S_{e}$ is the effective saturation, which is related to the relative saturation of the water phase by $S_{e}=\left(S_{w}-S_{w}^{r}\right) /\left(1-S_{w}^{r}\right)$ where $S_{w}^{r}$ is the residual saturation of the wetting phase and $S_{w}$ is the relative saturation of the water phase in the pore space of the porous medium $\left(\theta=S_{w} \phi\right.$ where $\phi$ represents the total connected porosity of the material), $S$ is the storage coefficient $\left(\mathrm{m}^{-1}\right)$, and $t$ is time. The hydraulic conductivity is related to the relative permeability $k_{r}$ and to the hydraulic conductivity at saturation $K_{s}$ by $K=k_{r} K_{s}$.

With the van Genuchten parametrization, we consider the soil as being saturated when the fluid pressure reaches the atmospheric pressure $(H=0)$. The effective saturation, the specific moisture capacity, the relative permeability, and the water content are defined by,

$$
\begin{aligned}
& S_{e}=\left\{\begin{array}{l}
1 /\left[1+|\alpha H|^{n}\right]^{m}, H<0 \\
1, H \geq 0
\end{array}\right. \\
& C_{e}=\left\{\begin{array}{l}
\frac{\alpha m}{1-m}\left(\phi-\theta_{r}\right) S_{e}^{\frac{1}{m}}\left(1-S_{e}^{\frac{1}{m}}\right)^{m}, H<0 \\
0, H \geq 0
\end{array}\right. \\
& k_{r}=\left\{\begin{array}{l}
S_{e}^{L}\left[1-\left(1-S_{e}^{\frac{1}{m}}\right)^{m}\right]^{2}, H<0 \\
1, H \geq 0
\end{array},\right. \\
& \theta=\left\{\begin{array}{l}
\theta_{r}+S_{e}\left(\phi-\theta_{r}\right), H<0 \\
\phi, H \geq 0
\end{array}\right.
\end{aligned}
$$

respectively and where $\theta_{r}$ is the residual water content $\left(\theta_{r}=S_{w}^{r} \phi\right)$, and $\alpha, n, m$, and $L$ are parameters that characterize the porous material with usually $m=1-1 / n$ (van Genuchten, 1980; Mualem, 1986).

The total electrical current density (generalized Ohm's law) is given by (Linde et al., 2007; Revil et al., 2007),

$\boldsymbol{j}=\sigma\left(S_{w}\right) E+\frac{\bar{Q}_{V}}{S_{W}} \boldsymbol{u}$,

where $\boldsymbol{u}=-\left(k_{r} K_{s} / \eta_{f}\right) \nabla H$ (and $\boldsymbol{u}=0$ when $S_{w} \rightarrow S_{w}^{r}$ ). The continuity equation is $\nabla \cdot \boldsymbol{j}=0$. The effect of the relative saturation upon the electrical conductivity can be determined using second Archie's law (Archie, 1942). Archie's second law is valid only when surface conductivity can be neglected. When the influence of surface conductivity cannot be neglected, more elaborate models (e.g., Waxman and Smits, 1968; Revil et al., 1998; Revil et al., 2002a) can be used instead.

\section{Infiltration test from a ditch}

In this section, we analyze the infiltration experiment reported by Suski et al. (2006) (see also Revil et al., 2002b for a preliminary test at the same site). This infiltration experiment was carried out in July 2004 at the test site of Roujan $\left(43^{\circ} 30^{\prime} \mathrm{N}\right.$ and $\left.3^{\circ} 19^{\prime} \mathrm{E}\right)$, which is located in the southern 
part France (Fig. 2) on the plain of the Hérault River. Eighteen piezometers were installed to a depth of $4 \mathrm{~m}$ on one side of the ditch (Fig. 2). The ditch itself was $0.8 \mathrm{~m}$ deep, $1.5 \mathrm{~m}$ wide, and $10 \mathrm{~m}$ long (Fig. 2a). The self-potential signals were monitored using a network of 41 non-polarising $\mathrm{Pb} / \mathrm{PbCl}_{2}$ electrodes (PMS9000 from SDEC) buried in the ground near the ground surface and a Keythley 2701 Multichannel voltmeter (with 80 channels). Suski et al. (2006) performed also an electrical resistivity tomography (ERT) along a section perpendicular to the ditch. The ERT allows to image the resistivity of the ground to a depth of $5 \mathrm{~m}$ (the acquisition was done with a set of 64 electrodes using the Wenner- $\alpha$ array and a spacing of $0.5 \mathrm{~m}$ between the electrodes). This ERT indicates that the resistivity of the soil was roughly equal to $20 \mathrm{Ohm} \mathrm{m}$ except for the first $50 \mathrm{~cm}$ where the resistivity was $\sim 100 \mathrm{Ohm}$ m.

The piezometers show that the water table was initially located at a constant depth of $2 \mathrm{~m}$ below the ground surface. During the experiment, $14 \mathrm{~m}^{3}$ of fresh water was injected in the ditch. The electrical conductivity of the injected water was $0.068 \mathrm{~S} \mathrm{~m}^{-1}$ at $20^{\circ} \mathrm{C}$. The infiltration experiment can be divided into three phases. Phase I corresponds to the increase of the water level with time in the ditch until a hydraulic head (measured from the bottom of the ditch) of $0.35 \mathrm{~m}$ was reached. The duration of this phase is $\approx 12 \mathrm{~min}$. In Phase II, the hydraulic head was maintained constant for $3 \mathrm{~h}$. At the beginning of phase III, we stopped the injection of water. This third phase corresponds therefore to the relaxation of the phreatic surface over time. The monitoring network of electrodes was activated at 07:28 LT (Local Time). The infiltration of the water in the ditch started at 08:48 LT (beginning of Phase I). The hydraulic and electrical responses were monitored during $6 \mathrm{~h}$ and $20 \mathrm{~min}$.

Laboratory experiments of the streaming potential coupling coefficients (see Suski et al., 2006) yields $C^{\prime}=-$ $5.8 \pm 1.1 \mathrm{mV} \mathrm{m}^{-1}$. The measurement was performed using the conductivity of the water injected into the ditch. All the hydrogeological material properties used in the following finite element numerical simulation are reported in Table 1. This table is using the hydrogeological model of Dagès et al. $(2007)^{1}$, which uses only hydrogeological inputs. The electrical conductivity of each soil layer and its streaming potential coupling coefficient are reported in Table 2 from the experimental and field data reported by Suski et al. (2006).

A 2-D numerical simulation was performed with a commercial finite element code (Comsol Multiphysics 3.3) along a cross-section perpendicular to the ditch (Fig. 3). Because of the symmetry of the problem with an axis of symmetry corresponding to the ditch, only one side of the ditch is modeled. We use the full formulation including capillary effects

\footnotetext{
${ }^{1}$ Dagès, C., Voltz, M., and Ackerer, P.: Parameterization and evaluation of the three-dimensional modelling approach to water table recharge from seepage losses in a ditch, Adv. Ground Water, submitted, 2007.
}

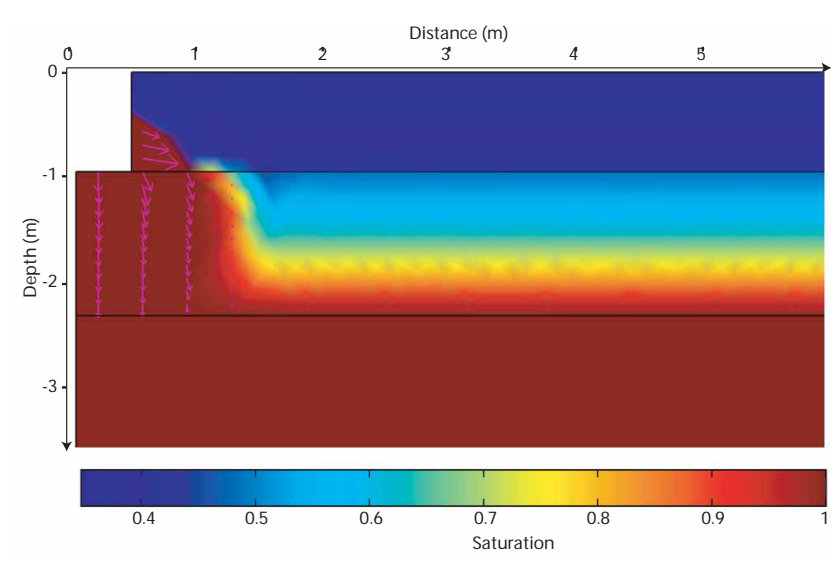

Fig. 3. Snapshot of the relative water saturation during the infiltration experiment. The saturation is determined using the finite element code Comsol Multiphysics 3.3. The arrows show the seepage velocities.

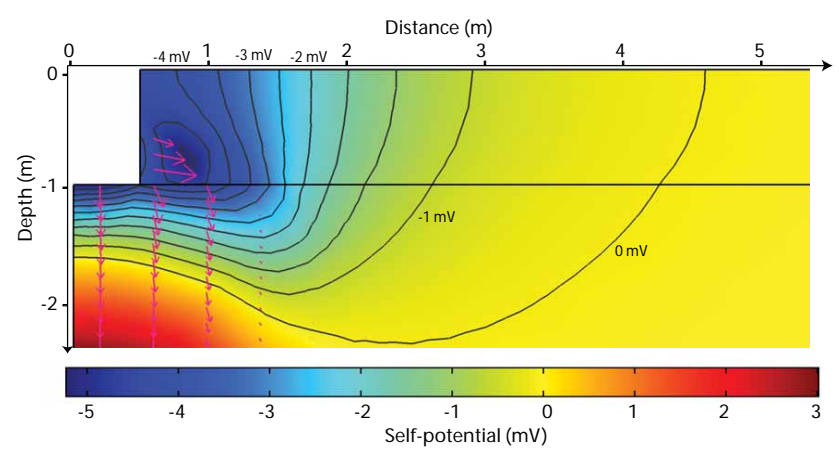

Fig. 4. Snapshot of the self-potential signal (in $\mathrm{mV}$ ) along a vertical cross-section perpendicular to the ditch. A negative anomaly is observed in the vicinity of the ditch.

in the vadose zone and therefore the influence of the capillary fringes using these material properties (see Sect. 2.2). Before the beginning of the injection of water in the ditch, the water table is located at a depth of $2 \mathrm{~m}$ with a stable capillarity fringe determined according to the van Genuchten parameters given in Table 1. Inside the ditch, we imposed a hydraulic head that varies over time according to the water level observing during the infiltration experiment in Stage I to III (see Suski et al., 2006). For electrical problem, we use insulating boundary condition $\boldsymbol{n} . j=0$ at the ground surface and at the symmetry plane (at $x=0$ ) and $\varphi \rightarrow 0$ at infinity, where, ideally, the reference electrode is supposed to be.

A snapshot of the distribution of the relative saturation of the water phase in the course of the infiltration is shown on Fig. 3. An example of the self-potential distribution at a given time during the infiltration experiment is shown on Fig. 4. Using a reference electrode placed at $10 \mathrm{~m}$ from the ditch, the self-potential anomaly computed in the vicinity of the ditch is negative in agreement with the measured self-potential signals (Fig. 5). 
Table 1. Porosity, $\phi$; residual water content $\theta_{r}$, van Genuchten parameters $n$ and $\alpha$ (we consider $L=0.5$ and $m=1-1 / n$ ), hydraulic conductivity at saturation $K_{S}$, anisotropy coefficient for the hydraulic conductivity at saturation for the four soil horizons in the ditch infiltration experiment (parameters taken from the hydrogeological computation performed by Dagès et al., 2007¹).

\begin{tabular}{cccccccc}
\hline Layer & $\begin{array}{c}\text { Depths } \\
(\mathrm{m})\end{array}$ & $\phi$ & $\theta_{r}$ & $\begin{array}{c}n \\
\left(\mathrm{~mm}^{-1}\right)\end{array}$ & $\begin{array}{c}\alpha \\
\left(\mathrm{m} \mathrm{s}^{-1}\right)\end{array}$ & $\begin{array}{c}K_{S} \\
\text { coefficient }\end{array}$ & Anisotropy \\
\hline 1 & $0-0.9$ & 0.37 & $5.1 \times 10^{-5}$ & 1.296 & 0.01360 & $1.11 \times 10^{-4}$ & 1.5 \\
2 & $0.9-2.2$ & 0.33 & $5.7 \times 10^{-4}$ & 1.572 & 0.00240 & $3.05 \times 10^{-5}$ & 1.0 \\
3 & $2.2-3.5$ & 0.31 & $5.5 \times 10^{-4}$ & 1.279 & 0.00520 & $5.00 \times 10^{-5}$ & 2.5 \\
4 & $3.5-6.0$ & 0.33 & $5.7 \times 10^{-4}$ & 1.572 & 0.00240 & $3.05 \times 10^{-5}$ & 1.0 \\
\hline
\end{tabular}

Table 2. Electrical conductivity and streaming current coupling coefficient for all soil layers involved in the model of the infiltration experiment.

\begin{tabular}{ccc}
\hline Soil layers & $\sigma\left(\mathrm{S} \mathrm{m}^{-1}\right)$ & $\bar{Q}_{V}\left(\right.$ in $\left.^{-3}\right)$ \\
\hline 1 & $0.01 \times S_{w}^{2(1)}$ & 0.33 \\
2 & $0.01 \times S_{w}^{2}(1)$ & 1.21 \\
3 & 0.05 & 0.74 \\
4 & 0.05 & 1.21 \\
\hline
\end{tabular}

(1) Using second Archie's law (Archie, 1942).

Table 3. Material properties used for the numerical simulation for the sinkhole case study.

\begin{tabular}{cccc}
\hline Material & $\begin{array}{c}K \\
\left(\mathrm{~m} \mathrm{~s}^{-1}\right)\end{array}$ & $\begin{array}{c}\rho \\
(\Omega \mathrm{m})\end{array}$ & $\bar{Q}_{V}\left(\mathrm{in}^{-3}\right)$ \\
\hline Loess & $10^{-8}$ & 77 & 8500 \\
Clay-with-flint & $10^{-10}$ & 10 & $0.98 \times 10^{6}$ \\
Chalk & $10^{-10}$ & 80 & $0.9 \times 10^{6}$ \\
Sinkhole & $10^{-7}$ & 60 & 850 \\
\hline
\end{tabular}

\section{Infiltration through sinkholes}

The second test site discussed in this paper is located in Normandy (Fig. 6). It was recently investigated by Jardani et al. (2006a, b) (see also recently Jardani et al., 2007, for a joint inversion of EM34 and self-potential data at the same site). Jardani et al. (2006a) performed 225 self-potential measurements in March 2005 with two $\mathrm{Cu} / \mathrm{CuSO}_{4}$ electrodes to map the self-potential anomalies in a field in which several sinkholes are clustered along a north-south trend (Fig. 6). They used a Metrix MX20 voltmeter with a sensitivity of $0.1 \mathrm{mV}$ and an internal impedance of $100 \mathrm{MOhm}$. The standard deviation on the measurements was smaller than one millivolt because of the excellent contact between the electrodes and the ground. The self-potential map shows a set of well-localized

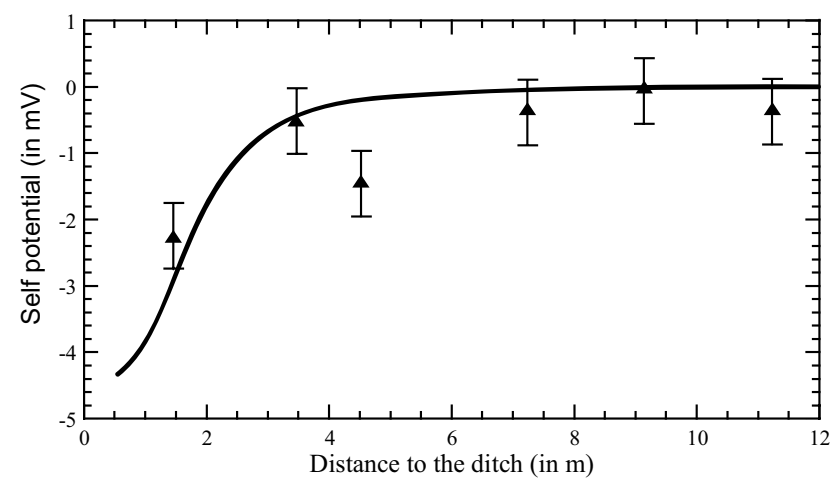

Fig. 5. Comparison between the measured self-potential signals (the filled triangles)along profile P3 (see Fig. 1) and the computed self-potential profile (the plain line). The error bars denote the standard deviation on the measurements.

negative self-potential anomalies associated with the direction along which the sinkholes are clustered. In this paper, we investigate only the profile $\mathrm{AB}$ (see location on Fig. 6) along which a high-resolution self-potential profile was obtained together with a resistivity profile.

The geology consists of a chalk bedrock covered by a loess layer exposed at the ground surface. A clay-with-flint layer corresponding to the weathered chalk layer is located between the loess layer and the chalk bedrock (Fig. 7). The shape of the interface between the loess and clay-with-flint formations is characterized by an electrical resistance tomography and few boreholes. In March 2005, the piezometers showed the presence of a small aquifer above this clay-withflint layer. Ground water flows above the clay-with-flint layer to the sinkholes. The depression of the water table above the sinkholes is largely due to the vertical infiltration of the water through the sinkholes but also reflects the depression of the clay-with-flint/loess interface at these locations. We use the material properties reported in Jardani et al. (2006a). Laboratory measurements of the streaming potential coupling coefficients yield $C^{\prime}=-4 \pm 2 \mathrm{mV} \mathrm{m}^{-1}$ (Jardani et al., 2006a). The boundary conditions used for the numerical simulations are as follows. At the ground surface $\left(\delta \Omega_{2}\right)$, 


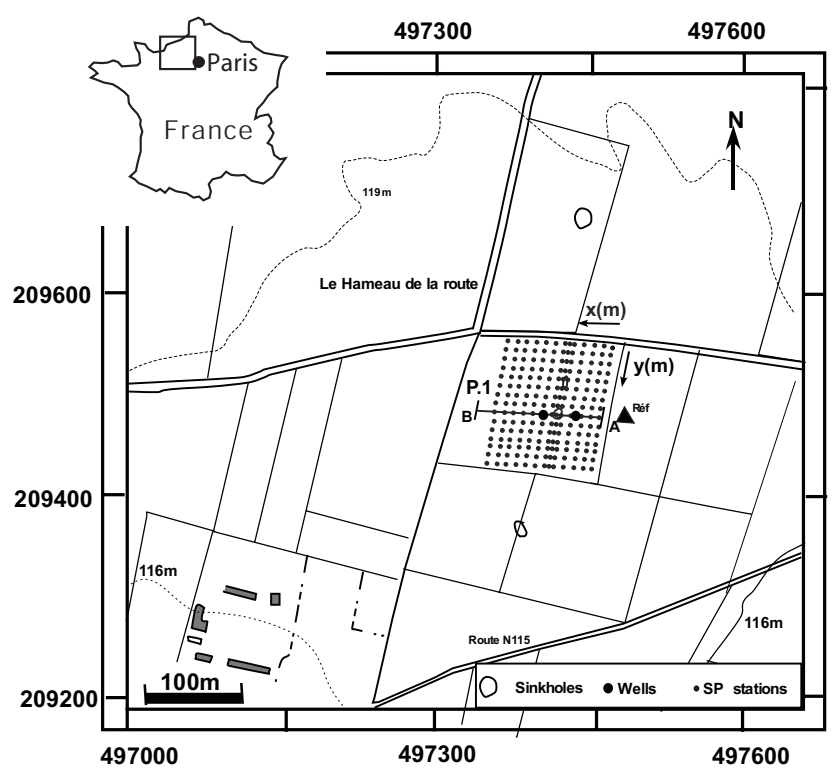

Fig. 6. The test site is located in Normandy, in the North-West of France, near the city of Rouen. The small filled circles indicate the position of the self-potential (SP) stations, Ref represents the reference station for the self-potential measurements, and P1 corresponds to the trace of the electrical resistivity survey. Note that the sinkholes are organized along a North-South trend.

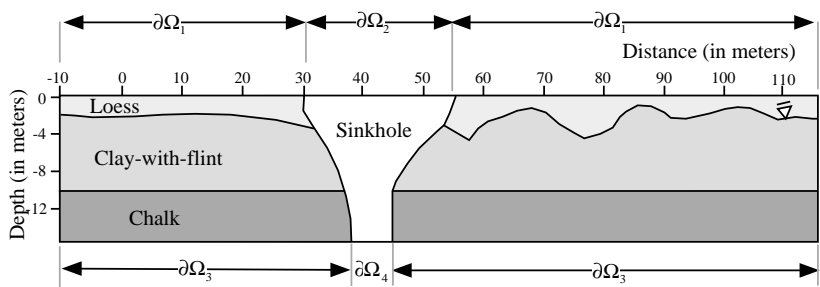

Fig. 7. Geometrical model used for the finite element calculation. The geometry of the interface between the loess and the clay with flint formation is determined from the resistivity tomogram. The material properties used for the calculations are discussed in the main text. The reference electrode is assumed to be located in the upper left-hand side corner of the profile.

we fixed the flux equal to the infiltration capacity of the sinkhole $\left(10^{-7} \mathrm{~m}^{2} \mathrm{~s}^{-1}\right.$, that is $3 \mathrm{~m}$ year $\left.{ }^{-1}\right)$ because of the observed runoff of water in sinkholes in this area (Jardani et al., 2006a). The geometry of the system is shown on Fig. 7 . At the upper boundary $\delta \Omega_{1}$, the hydraulic flux is set equal to the rain rate $\left(0.6 \mathrm{~m} \mathrm{yr}^{-1}\right)$, opposite vertical sides of the system are characterized by impermeable boundary conditions $\boldsymbol{n} . u=0$ (because the infiltration is mainly vertical). At the lower boundary $\delta \Omega_{4}$, we fixed the flux for the ground water equal to the exfiltration capacity of the sinkhole. The lower boundary $\delta \Omega_{3}$ is considered to be impermeable. For the electrical problem, we use the insulating boundary condition, $\boldsymbol{n} . j=0$ at the interface between the atmosphere and the

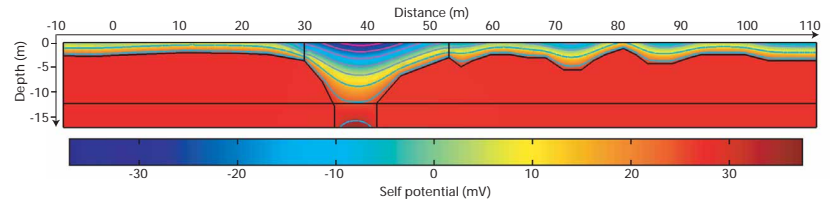

Fig. 8. 2-D finite element simulation of the self-potential (expressed in $\mathrm{mV}$ ) along the resistivity profile $\mathrm{AB}$ (see location on Fig. 5). The reference electrode is assumed to be located in the upper left-hand side corner of the profile.



Fig. 9. The reference electrode is assumed to be located in the upper left-hand side corner of the profile. The error bar $( \pm 1 \mathrm{mV})$ is determined from the standard deviation determined in the field for the self-potential measurements.

ground. The reference electrode for the self-potential signal is located at $x=-10 \mathrm{~m}$ at the ground surface. In order to match the observed data, one should choose the same reference in the numerical modeling.

The result of the numerical simulations is shown on Fig. 8 . A comparison between the self-potential data and the simulated self-potential data is shown on Fig. 9 along the profile AB. Despite some minor variations between the model and the measured data (likely due to the two-dimensional geometry used in the model while the real geometry is threedimensional), the model is able to capture the shape of the self-potential anomalies.

\section{Flow in a Paleochannel}

Negative self-potential anomalies associated with the preferential flow of water in permeable pathways have been reported by Fournier (1989), Finizola et al. (2003), and Revil et al. (2004). An investigation of the self-potential signals associated with fluid flow in a buried paleochannel was reported by Revil et al. (2005b). Located on the southeast of France, the Rhône river delta (Camargue) is one of the most important catchment in Western Europe. The area investigated here, Méjanes, is located to northwest to a saline pond named Vaccarès (Fig. 10). This plain is formed mainly 


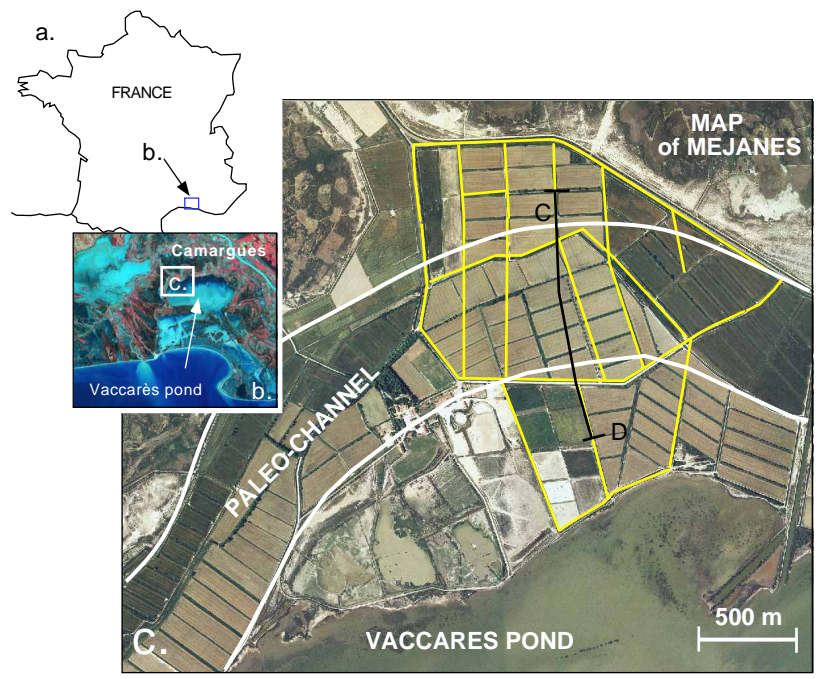

Fig. 10. Localization of the test site in Camargue, in the delta of the Rhône river. The profile CD corresponds to the resistivity profile shown on Fig. 10. The yellow plain lines represent self-potential profiles described in Revil et al. (2005b).

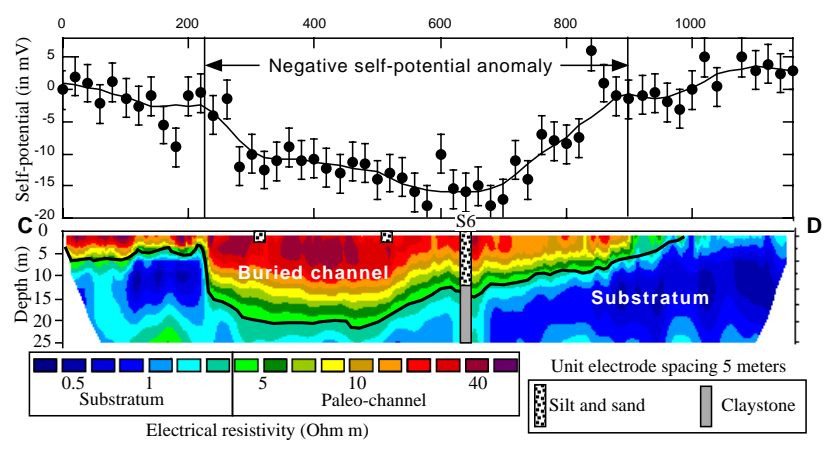

Fig. 11. Electrical resistivity tomography and self-potential anomaly along a cross-section perpendicular to the paleochannel. We observe a negative self-potential anomaly above the position of the buried paleochannel. According to Revil et al. (2005b), the contrast of resistivity between the plaeochannel and the surrounding sediment is due to a strong contrast of resistivity between the pore water filling the paleochannel and the pore water filling the surrounding sediments.

by fluvial deposits of an ancient channel of the Rhône river named the Saint-Ferréol Channel. In principle, the salinity of the Méjanes area is high due to saltwater intrusion in the vicinity of the saline pond. The self-potential voltages were mapped with two non-polarising $\mathrm{Pb} / \mathrm{PbCl}_{2}$ electrodes (PMS9000 from SDEC) and a Metrix MX20 voltmeter with a sensitivity of $0.1 \mathrm{mV}$ and an internal impedance of $100 \mathrm{MOhm}$.

Electrical resistivity tomography indicates that resistivity of the sediment outside the buried paleo-channel is in the range 0.4-1.2 $\Omega$ (Fig. 11). According to Revil et al. (2005b),

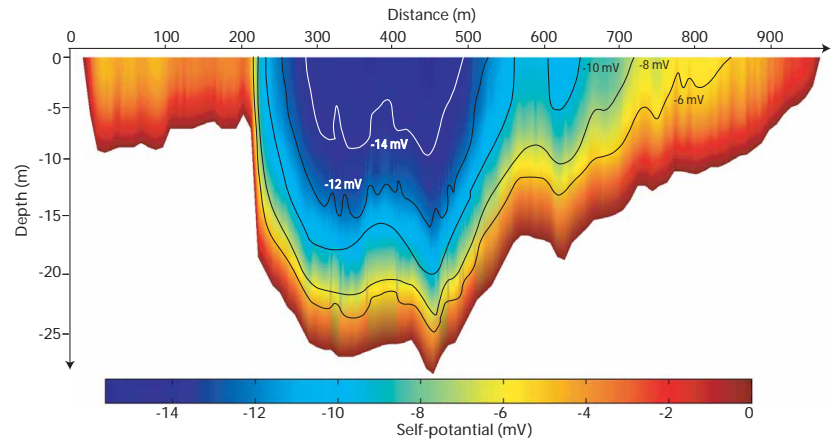

Fig. 12. Computation of the self-potential signals (expressed in $\mathrm{mV}$ ) inside the paleochannel across a cross-section perpendicular to the paleochannel. The computation is performed using 3-D simulation of the coupled hydroelectric problem in the paleochannel. The reference electrode is assumed to be located in the upper lefthand side corner of the profile. Note that the interface between the paleochannel and the surrounding body is an equipotential.

this implies that the resistivity of the pore water is in the range $0.1-0.4 \Omega \mathrm{m}$ in the paleochannel. Therefore, the ground water in the paleochannel is approximately ten time less saline than the pore water contained in the surrounding sediments. Inside the paleo-channel, the streaming potential coupling coefficient is equal to $-1.2 \pm 0.4 \mathrm{mV} \mathrm{m}^{-1}$ based on the range of values for the resistivity of the pore water and laboratory measurements given by Revil et al. (2005b). The magnitude of the streaming potential coupling coefficients in the surrounding sediments is $<0.2 \mathrm{mV} \mathrm{m}^{-1}$, so much smaller than inside the paleochannel and will be neglected in the numerical simulation.

For the numerical simulations, we use a permeability equal to $10^{-10} \mathrm{~m}^{2}$, a streaming potential coupling coefficient equal to $-1.2 \pm 0.4 \mathrm{mV} \mathrm{m}^{-1}$, and an electrical conductivity equal to $0.035 \mathrm{~S} \mathrm{~m}^{-1}$ for the materials filling the paleochannel. At the entrance of the paleochannel, we impose a flux equal to $8 \times 10^{-4} \mathrm{~m} \mathrm{~s}^{-1}$. We assume that the sediment is impermeable outside the paleochannel and we use the continuity of the normal component of the electrical current density through the interface between the paleochannel and the surrounding sediments.

The finite element simulation is done with Comsol Multiphysics 3.3 in steady-state conditions. The result is displayed on Fig. 12. This figure shows that the equipotentials are nearly parallel to the interface between the paleochannel and the surrounding sediments. A negative self-potential anomaly is associated with the presence of the paleochannel because of the horizontal flow of the ground water. Comparison between the model and the measured self-potential data is shown on Fig. 13. Again, the model is clearly able to reproduce the shape of the negative self-potential anomaly observed just above the paleochannel. 


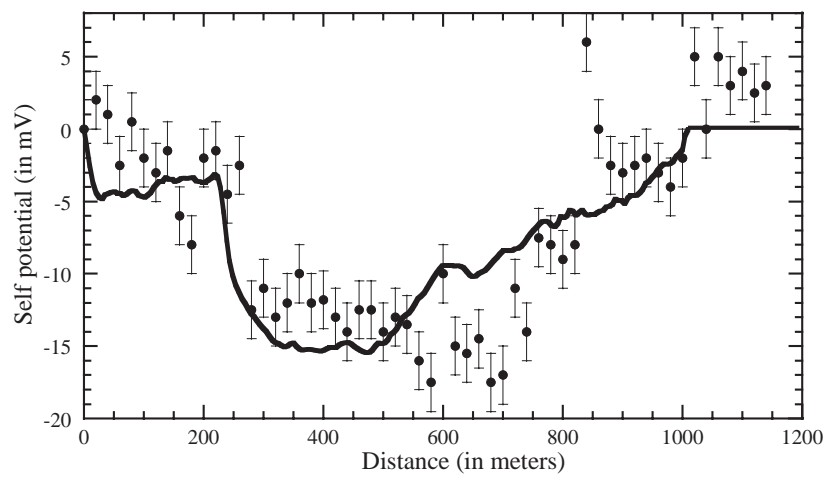

Fig. 13. Comparison between the measured self-potential signals (reported in Revil et al., 2005b) along a cross-section perpendicular to the paleochannel (the filled circles) and the computed selfpotential profile using the finite element code Comsol Multiphysics 3.3. The error bars were determined from the standard deviation determined in the field for the self-potential measurements.

\section{Concluding statements}

Self-potential signals can be computed directly from the seepage velocity and the excess of charge per unit pore volume of the porous medium. This excess of electrical charge can be determined from the streaming potential coupling coefficient at saturation and the hydraulic conductivity through laboratory measurements. In saturated conditions, the macroscopic formulation we used is similar to the classical formulation except that it accounts for the permeability of the formations upon the streaming current density. In addition, the new formulation can be extended to unsaturated conditions and can therefore be used to determine the effect of the capillary fringe, for example, upon the measured selfpotential signals. Numerical simulations performed at different test sites shows that our formulation can be used to represent quantitatively the self-potential signals in field conditions. In this regard, the analysis provided in this paper paves the way for future inverse reconstruction of important hydrological parameters (permeability, flow velocity, and aquifer geometry) from collocated self-potential and electrical resistivity measurements on the ground's surface or in boreholes. The inversion of self-potential signals is a relatively new field (see Jardani et al., 2006b; Minsley et al., 2007; Mendonça, 2007 ) with a high number of potential applications in hydrogeology, and especially to pumping tests (Rizzo et al., 2004; Suski et al., 2004; Titov et al., 2005; and Straface et al., 2007) as well as the scale of catchments (Linde et al., 2007). The effect of the heterogeneity of the resistivity and the coupling coefficient will be investigated in a forthcoming work.

Acknowledgements. This work was supported by the CNRS (The French National Research Council), by ANR Projects ERINOH and POLARIS. We thank ANR (Agence Nationale de la Recherche), the French National Program "ECosphère Continentale" and INSU-CNRS for their financial supports. The Ph-D Thesis of
A. Bolève is supported by SOBESOL and ANRT. We thank Maxwell Meju and an anonymous referee for their constructive comments.

Edited by: C. Hinz

\section{References}

Aizawa, K.: A large self-potential anomaly and its changes on the quiet Mt. Fuji, Japan, Geophys. Res. Lett., 31, L05612. doi:10.1029/2004GL019462, 2004

Archie, G. E.: The electrical resistivity log as an aid in determining some reservoir characteristics, Trans. AIME, 146, 54-61, 1942.

Arora T., Linde N., Revil A., and Castermant J.: Non-intrusive determination of the redox potential of contaminant plumes by using the self-potential method, J. Contaminant Hydrol., 92, 274 292, doi:10.1016/j.jconhyd.2007.01.018, 2007.

Aubert, M., Dana, I. N., Gourgaud, A.: Internal structure of the Merapi summit from self-potential measurements, J. Volcanol. Geotherm. Res., 100(1), 337-343, 2000.

Aubert, M. and Atangana, Q. Y.: Self-potential method in hydrogeological exploration of volcanic areas, Ground Water, 34, 1010 1016, 1996.

Bedrosian, P. A., Unsworth, M. J., and Johnston, M. J. S.: Hydrothermal circulation at Mount St. Helens determined by selfpotential measurements, J. Volcanol. Geotherm. Res., 160(1-2), 137-146, 2007.

Birch F. S.: Testing Fournier's method for finding water table from self-potential, Ground Water, 31, 50-56, 1993.

Bolève, A., Crespy, A., Revil, A., Janod, F., and Mattiuzzo, J L.: Streaming potentials of granular media. Influence of the Dukhin and Reynolds numbers, J. Geophys. Res., 112, B08204, doi:10.1029/2006JB004673, 2007.

Bogoslovsky, V. A. and Ogilvy, A. A.: The study of streaming potentials on fissured media models, Geophys Prospecting, 51, 109-117, 1972.

Bogoslovsky, V. A. and Ogilvy, A. A.: Deformation of natural electric fields near drainage structures, Geophys. Prospecting, 21, 716-723, 1973.

Colangelo, G., Lapenna, V., Perrone, A., et al.: 2D Self-Potential tomographies for studying groundwater flows in the Varco d'Izzo landslide (Basilicata, southern Italy), Engineering Geology, 88(3-4), 274-286, 2006.

Comsol: http://www.comsol.com/, 2007.

Crespy, A., Bolève, A., and Revil, A.: Influence of the Dukhin and Reynolds numbers on the apparent zeta potential of granular media, J. Colloid Interface Sci., 305, 188-194, 2007.

Ernstson, K. and Scherer, H. U.: Self-potential variations with time and their relation to hydrogeologic and meteorological parameters, Geophysics, 51, 1967-1977, 1986.

Finizola, A., Lénat, J. F., Macedo, O., Ramos, D., Thouret, J. C., and Sortino, F.: Fluid circulation and structural discontinuities inside Misti volcano (Peru) inferred from self-potential measurements, J. Volcanol. Geotherm. Res., 135, 343-360, 2004.

Finizola, A., Sortino, S., Lénat, J.-F., Aubert, M., Ripepe, M., Valenza, M.: The summit hydrothermal system of Stromboli. New insights from self-potential, temperature, $\mathrm{CO} 2$ and fumarolic fluid measurements. Structural and monitoring impli- 
cations, Bull. Volcanol., 65, 486-504, doi:10.1007/s00445-0030276-z, 2003.

Fournier, C.: Spontaneous potentials and resistivity surveys applied to hydrogeology in a volcanic area: case history of the Chaîne des Puys (Puy-de-Dôme, France), Geophys. Prospecting, 37, 647$668,1989$.

Guichet, C., Jouniaux, L., and Pozzi, J.-P.: Streaming potential of a sand column in partial saturation conditions, J. Geophys. Res., 108, 2141-2153, 2003.

Ishido, T. and Mizutani, H.: Experimental and theoretical basis of electrokinetic phenomena in rock-water systems and its application to geophysics, J. Geophys. Res., 86, 1763-1775, 1981.

Ishido, T.: Electrokinetic mechanism for the "W"-shaped selfpotential profile on volcanoes, Geophys. Res. Lett., 31, L15616. doi:10.1029/2004GL020409, 2004.

Jardani, A., Revil, A., Santos, F., Fauchard, C., and Dupont, J. P.: Detection of preferential infiltration pathways in sinkholes using joint inversion of self-potential and EM-34 conductivity data, Geophys. Prospecting, 55, 1-11, doi:10.1111/j.13652478.2007.00638.x, 2007.

Jardani A., Dupont, J. P., and Revil, A.: Self-potential signals associated with preferential ground water flow pathways in sinkholes, J. Geophys. Res., 111, B09204, doi:10.1029/2005JB004231, $2006 \mathrm{a}$.

Jardani, A., Revil, A., and Dupont, J. P.: 3D self-potential tomography applied to the determination of cavities, Geophys. Res. Lett., 33, L13401, doi:10.1029/2006GL026028, 2006b.

Jiang, Y. G., Shan, F. K., Jin, H. M., Zhou, L. W., and Sheng, P.: A method for measuring electrokine tic coefficients of porous media and its potential application in hydrocarbon exploration, Geophys. Res. Lett., 25(10), 1581-1584, 1998.

Jouniaux, L. and Pozzi, J.-P.: Streaming potential and permeability of saturated sandstones under triaxial stress: Consequences for electrotelluric anomalies prior to earthquakes, J. Geophys. Res., 100, 10 197-10 209, 1995.

Kosmulski, M. and Dahlsten, P.: High ionic strength electrokinetics of clay minerals. Colloids and Surfaces A: Physicochem. Eng. Aspects, 291, 212-218, 2006.

Kilty, K. T. and Lange, A. L.: Electrochemistry of natural potential processes in karst. In: Proc 3rd Conf on Hydrogeology, Ecology, Monitoring, and Management of Groundwater in Karst Terranes, 4-6 Dec 1991, Maxwell House, Clarison, Nashville, Tennessee, 163-177, 1991.

Lachassagne, P. and Aubert, M.: Etude des phénomènes de polarisation spontanée (PS) enregistrées dans un sol lors de transferts hydriques verticaux, Hydrogéologie, 1, 7-17, 1989.

Lapenna, V., Lorenzo, P., Perrone, A., Piscitelli, S., Rizzo, E., and Sdao, F.: High resolution geoelectrical tomographies in the study of the Giarrosa landslide (Potenza, Basilicata), Bull. Eng. Geol. Environ., 62, 259-268, 2003.

Lapenna, V., Lorenzo, P., Perrone, A., Piscitelli, S., Rizzo, E., and Sdao, F.: 2D electrical resistivity imaging of some complex landslides in the Lucanian Appenine chain, Southern Italy, Geophysics, 70(3), B11-B18, 2005.

Linde, N. and Revil, A.: Inverting residual self-potential data for redox potentials of contaminant plumes, Geophys. Res. Lett., 34, L14302, doi:10.1029/2007GL030084, 2007.

Linde, N., Jougnot, D., Revil, A., Matthäi, S., Arora, T., Renard, D., and Doussan, C.: Streaming current generation in two-phase flow conditions, Geophys. Res. Lett., 34(3), L03306, doi:10.1029/2006GL028878, 2007a.

Linde, N., Revil, A., Bolève, A., Dagès, C., Castermant, J., Suski, B., and Voltz, M.: Estimation of the water table throughout a catchment using self-potential and piezometric data in a Bayesian framework, J. Hydrol., 334, 88-98, 2007 b.

Maineult, A., Bernabé, Y., and Ackerer, P.: Detection of advected concentration and $\mathrm{pH}$ fronts from self-potential measurements, $\mathrm{J}$. Geophys. Res., 110(B11), B11205, doi:10.1029/2005JB003824, 2005.

Mendonça, C. A.: A forward and inverse formulation for selfpotential data in mineral exploration, Geophysics, in press, 2007.

Minsley, B. J., Sogade, J., and Morgan, F. D.: Three-dimensional self-potential inversion for subsurface DNAPL contaminant detection at the Savannah River Site, South Carolina, Water Resour. Res., 43, W04429, doi:10.1029/2005WR003996, 2007.

Morgan, F. D., Williams, E. R., and Madden, T. R.: Streaming potential properties of westerly granite with applications, J. Geophys. Res., 94, 12 449-12 461, 1989.

Mualem, Y.: Hydraulic conductivity of unsaturated soils: prediction and formulas, in: Methods of Soil Analysis, edited by: Klute, A., American Society of Agronomy, Madison, Wisconsin, 9(1), 799-823, 1986.

Naudet, V., Revil, A., and Bottero, J.-Y.: Relationship between self-potential (SP) signals and redox conditions in contaminated groundwater, Geophys. Res. Lett., 30(21), 2091, doi:10.1029/2003GL018096, 2003.

Naudet, V., Revil, A., Rizzo, E., Bottero, J.-Y., and Bégassat, P.: Groundwater redox conditions and conductivity in a contaminant plume from geoelectrical investigations, Hydrol. Earth Syst. Sci., 8(1), 8-22, 2004.

Naudet, V. and Revil, A.: A sandbox experiment to investigate bacteria-mediated redox processes on self-potential signals, Geophys. Res. Lett., 32, L11405, doi:10.1029/2005GL022735, 2005.

Nourbehecht, B.: Irreversible thermodynamic effects in inhomogeneous media and their application in certain geoelectric problems. Ph.D Thesis, MIT Cambridge, 1963.

Ogilvy, A. A.: Studies of underground water movement, Geol. Surv. Can. Rep., 26, 540-543, 1967.

Ogilvy, A. A., Ayed, M. A., and Bogoslovsky, V. A.: Geophysical studies of water leakage from reservoirs, Geophys. Prospect, 22, 36-62, 1969.

Onsager, L.: Reciprocal relations in irreversible processes, 1. Phys. Rev. 37, 405-426, 1931.

Perrone, A., Iannuzzi, A., Lapenna, V., et al.: High resolution electrical imaging of the Varco d'Izzo earthflow (southern Italy), J. Appl. Geophys., 56(1), 17-29, 2004.

Perrier, F. and Raj Pant, S.: Noise reduction in long term selfpotential monitoring with traveling electrode referencing, Pure Appl. Geophys., 162, 165-179, 2005.

Perrier, F. and Morat, P.: Characterization of electrical daily variations induced by capillary flow in the non-saturated zone, Pure Appl. Geophys., 157, 785-810, 2000.

Petiau, G.: Second generation of lead-lead chloride electrodes for geophysical applications, Pure Appl. Geophys., 157, 357-382, 2000.

Revil, A. and Linde, N.: Chemico-electromechanical coupling in microporous media, J. Colloid Interface Sci., 302, 682-694, 2006. 
Revil, A., Linde, N., Cerepi, A., Jougnot, D., Matthäi, S., and Finsterle, S.: Electrokinetic coupling in unsaturated porous media, J. Colloid Interface Sci., 313(1), 315-327, doi:10.1016/j.jcis.2007.03.037, 2007.

Revil, A., Leroy, P., and Titov, K.: Characterization of transport properties of argillaceous sediments. Application to the Callovo-Oxfordian Argillite, J. Geophys. Res., 110, B06202, doi:10.1029/2004JB003442, 2005a.

Revil, A., Cary, L., Fan, Q., Finizola, A., and Trolard, F. Selfpotential signals associated with preferential ground water flow pathways in a buried paleo-channel, Geophys. Res. Lett., 32, L07401, doi:10.1029/2004GL022124, 2005b.

Revil, A. and Cerepi, A.: Streaming potential in twophase flow condition, Geophys. Res. Lett., 31(11), L11605, doi:1029/2004GL020140, 2004.

Revil, A. and Leroy, P.: Governing equations for ionic transport in porous shales, J. Geophys. Res., 109, B03208, doi:10.1029/2003JB002755, 2004.

Revil, A., Finizola, A., Sortino F., and Ripepe, M.: Geophysical investigations at Stromboli volcano, Italy. Implications for ground water flow and paroxysmal activity, Geophys. J. Int., 157(1), 426-440, 2004a.

Revil, A., Naudet, V., and Meunier, J. D.: The hydroelectric problem of porous rocks: Inversion of the water table from selfpotential data, Geophys. J. Int., 159, 435-444, 2004.

Revil, A., Naudet, V., Nouzaret, J., and Pessel, M.: Principles of electrography applied to self-potential electrokinetic sources and hydrogeological applications, Water Resour. Res., 39(5), 1114, doi:10.1029/2001WR000916, 2003.

Revil, A., Hermitte, D., Spangenberg, E., and Cochémé, J. J.: Electrical properties of zeolitized volcaniclastic materials, J. Geophys. Res., 107(B8), 2168, doi:10.1029/2001JB000599, 2002a.

Revil, A., Hermitte, D., Voltz, M., Moussa, R., Lacas, J.G., Bourrié, G., and Trolard, F.: Self-potential signals associated with variations of the hydraulic head during an infiltration experiment, Geophys. Res. Lett., 29(7), 1106, doi:10.1029/2001GL014294, 2002b.

Revil, A., Pezard, P. A., and Glover, P. W. J.: Streaming potential in porous media. 1. Theory of the zeta-potential, J. Geophys. Res., 104(B9), 20 021-20 031, 1999a.

Revil, A., Schwaeger, H., Cathles, L. M., and Manhardt, P.: Streaming potential in porous media. 2. Theory and application to geothermal systems, J. Geophys. Res., 104(B9), 20 033-20 048, 1999b.
Revil, A., Cathles, L. M., Losh, S., and Nunn, J. A.: Electrical conductivity in shaly sands with geophysical applications, J. Geophys. Res., 103(B10), 23 925-23 936, 1998.

Richards, L. A.: Capillary conduction of liquids through porous media, Physics, 1, 318-333, 1931.

Rizzo, E., Suski, B., Revil, A., Straface, S., and Troisi, S.: Selfpotential signals associated with pumping-tests experiments, J. Geophys. Res., 109, B10203, doi:10.1029/2004JB003049, 2004.

Santos, F. A. M., Almeda, E. P., Castro, R., Nolasco, R., and Mendes-Victor, L.: A hydrogeological investigation using EM34 and SP surveys, Earth Planets Space, 54, 655-662, 2002.

Sill, W. R.: Self-potential modeling from primary flows, Geophysics, 48(1), 76-86, 1983.

Straface, S., Falico, C., Troisi, S., Rizzo, E., and Revil, A.: Estimating of the transmissivities of a real aquifer using self potential signals associated with a pumping test, Ground Water, 45(4), 420-428, 2007.

Suski, B., Revil, A., Titov, K., Konosavsky, P., Voltz, M., Dagès, C., and Huttel, O.: Monitoring of an infiltration experiment using the self-potential method, Water Resour. Res., 42, W08418, doi:10.1029/2005WR004840, 2006.

Suski, B., Rizzo, E., and Revil, A.: A sandbox experiment of selfpotential signals associated with a pumping-test, Vadose Zone Journal, 3, 1193-1199, 2004.

Titov, K., Revil, A., Konasovsky, P., Straface, S., and Troisi, S.: Numerical modeling of self-potential signals associated with a pumping test experiment, Geophys. J. Int., 162, 641-650, 2005.

van Genuchten, M. T.: A closed-form equation for predicting the hydraulic conductivity of unsaturated soils, Soil Sci. Soc., 44, 892-898, 1980.

Waxman, M. H. and Smits, L. J. M.: Electrical conduction in oilbearing sands, Society of Petroleum Engineers Journal, 8, 107122, 1968.

Wishart, D. N., Slater, L. D., and Gates, A. E.: Self potential improves characterization of hydraulically-active fractures from azimuthal geoelectrical measurements, Geophys. Res. Lett., 33, L17314, doi:10.1029/2006GL027092, 2006.

Wurmstich, B., Morgan, F. D., Merkler, G.-P., and Lytton, R.: Finite-element modelling of streaming potential due to seepage: study of a dam. Soc. Explor, Geophysicists Technical Program Expanded Abstracts, 10, 542-544, 1991. 